REVIEWARTICLE

\section{Polymer Infiltrated Ceramic Hybrid Composites as Dental Materials}

\author{
Cheng Xie "1", Jian-Feng Zhang ${ }^{211}$ and Shibao $\mathrm{Li}^{3^{3}}$ \\ ${ }^{1}$ State Key Laboratory of Military Stomatology, Department of Prosthodontics, School of Stomatology, \\ Fourth Military Medical University, Xi'an 710032, P.R. China \\ ${ }^{2}$ Department of Comprehensive Dentistry \& Biomaterials, School of Dentistry, Louisiana State \\ University Health Sciences Center, USA \\ ${ }^{3}$ State Key Laboratory of Military Stomatology, Department of Dental Materials, School of \\ Stomatology, Fourth Military Medical University, Xi'an 710032, P.R. China. \\ "Equal contribution.
}

\section{G Open Access}

Citation: Xie, C, Zhang JF, Li S. Polymer Infiltrated Ceramic Hybrid Composites as Dental Materials. Oral Health and Dental Studies. 2018; 1(1):2.

Received: August 14, 2017 Accepted: January 23, 2018 Published: February 14, 2018

Copyright: @ $\odot 2018 \mathrm{Li}$ et al. This is an open access article distributed under the terms of the Creative Commons Attribution License, which permits unrestricted use, distribution, and reproduction in any medium, provided the original author and source are credited.

\section{Corresponding author:}

Shibao Li, Department of Dental Materials, School of Stomatology, Fourth Military Medical University, P.R. China.

E-mail: lishibao@fmmu.edu.cn

\begin{abstract}
Advancement in dental materials has made it possible to manufacture polymer/ceramic composites for direct and indirect restoration. However, applying polymer/ceramic composites to durable and biomimetic assemblies and maintaining their tailored-made functions as dental materials comes with opportunities and challenges for practical implementation. This article reviews the state-of-the-art polymer infiltrated ceramic hybrid composites, with respect to the composition, fabrication techniques, and structureproperty analysis. In addition, this article elaborates the performance of polymer infiltrated ceramic hybrid composites, in particular the correlation among composites, ceramic, polymer structure, mechanical performance as well as machinability. Finally, limitations of current materials, fabrication techniques, performance and machinability as well as research/clinical understanding are addressed to set forward possible resolutions.
\end{abstract}

\section{Keywords}

Polymer, ceramic, infiltration, composites

\section{Introduction}

Dental materials with comparable mechanical performance and esthetic effects to that of natural human enamel and dentin are in demand. Recent trend has witnessed an increasing demand of computer-aided design/manufacturing (CAD/CAM) technology for ceramic and composite materials in esthetic dentistry. ${ }^{1,2}$ For more than a century, dental ceramics have been used for indirect restorations, such as crown and bridges. Despite their natural tooth appearance, they come with higher elastic modulus $(E)$ than that of enamel, for example, the $E$ of zirconia or alumina is in a range of 200-380 GPa in comparison with 20-84 GPa of that of enamel and dentin. Despite the tougher ceramic structure, such as zirconia, alumina, and glass, ceramic lithium disilicate is extensively used in dentistry. All-ceramic system particularly those with veneer porcelains suffer a relatively high failure rate due to brittleness of the veneering layer, which shortens its service life than metal-ceramic restorations. ${ }^{3}$ Adversely, the hardness of veneering materials may cause excessive wear of the opposing teeth producing sensitivity and occlusal imbalance, which is not desirable. ${ }^{4}$ Another major technical challenge registered with ceramic restorations is the chipping problem during fabrication due to their brittleness. Repairs of such failure are usually carried out using resin composite materials.

Compared to conventional materials, polymer/ceramic hybrid composites have the potential to tailor the desirable properties that individual component can offer. While ceramic materials show excellent mechanical, biomechanical, tribological, and high temperature stability properties, polymers are an example of materials with higher ductility and low elastic 
modulus. Therefore, the development of polymer infiltrated ceramic composites tailoring individual components' performance offers a promising dental material. ${ }^{5,6}$ VITA (VITA Zahnfabrik, Bad Säckingen, Germany) lunched Enamic-a resin-composite hybrid composite-through the infiltration of a monomer mixture to pre-sintered ceramic network.

Mixing of polymer and ceramic on the molecular level can be thought of as a route to overcome the brittleness of ceramic while enhance the strength of the polymer. The classic approach to combine polymer and ceramic is the inclusion of ceramic particles in a polymer matrix. $^{7}$ The resultant materials have improved strength, elastic properties, and tribological resistance. ${ }^{8-10}$ Ceramic particles reinforced dental resin-composites are frequently used in dental restorations. ${ }^{11}$ There are several articles that have extensively reviewed dental composites prepared by the conventional route. ${ }^{12-15}$ This review focuses on a route that allows molecular dispersion of polymer chains into ceramic matrix by infiltration.

\section{Polymer infiltrated ceramic hybrid composites}

The polymer infiltration method was inspired by the composition of real teeth enamel, which consists of inorganic and organic components. ${ }^{16}$ The properties of materials can be improved using this structural approach, i.e. the use of two self-interpenetrating networks. The preparation of the first network of ceramic framework is schematically presented in Figure $1 .{ }^{17}$ As a result the weak point of common polymer ceramic composites and unbounded ceramic particles can be prevented. Replacing the loose ceramic particles in the polymer matrix with a stable ceramic matrix with higher strength, higher elastic modulus, higher toughness, and better wear resistance is possible. ${ }^{18-20}$ Higher fracture toughness, higher crack resistance, and higher mechanical properties in general have been reported on similar structured polymer ceramic composites used for tissue engineering..$^{21,22}$ The interpenetrating microstructure can be reached by infiltrating liquid monomers in a porous ceramic network. Similar to classic polymer ceramic composites, the ceramic surface can be modified to improve interfacial strength between the organic polymer and the inorganic ceramic phase. ${ }^{23}$ After the porous ceramic is completely filled with the monomer, the crosslinking of the monomer is initiated by a thermal activation step. Poly(methyl methacrylate) monomer infiltrated micropores in partially sintered zirconia compacts (PSZC) under vacuum to form a hybrid composite. ${ }^{5}$ The fracture surface of the hybrid composites exhibited PMMA pullouts (Figure 2). However, the amount of monomer in the compacts is limited and restriction of the monomer mobility is high because of the spatial separation and capillary forces.

Infiltrating polymers into ceramic compacts can be achieved by three different methods: solvent infiltration, melt infiltration, and monomer and initiator infiltration followed by in-situ polymerization inside the ceramic pores. In both solvent and in-situ polymerization, the alumina bars were initially vacuumed for $1 \mathrm{~h}$, and the polymer solution or the monomers were then introduced through feeding funnel. The polymerization starts by heating the monomer solution to $60^{\circ} \mathrm{C}$. In melt infiltration, the alumina bars covered by solid polymer films were vacuumed for $1 \mathrm{~h}$ and then heated to $150-200^{\circ} \mathrm{C}$, thereby allowing the polymer melt to flow into the alumina pores. ${ }^{24}$

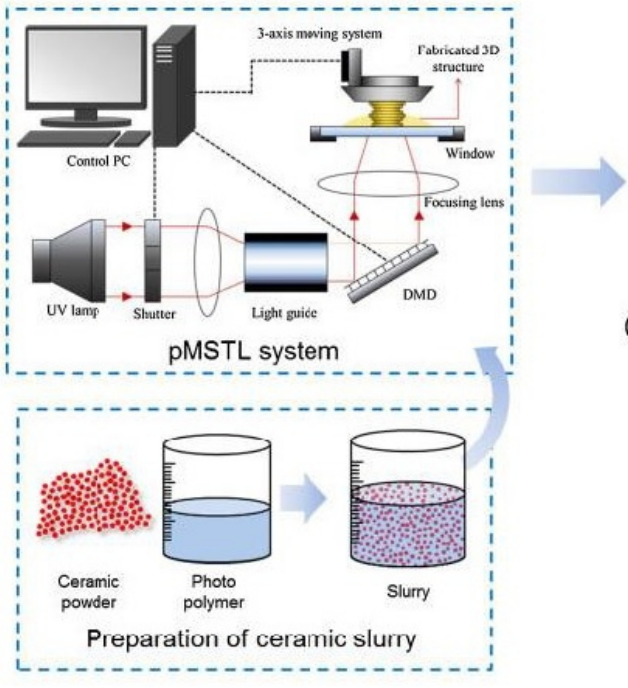

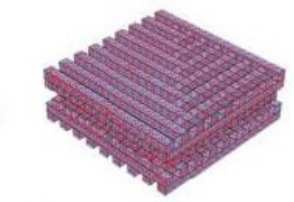

Composite structure (Ceramic + Photo polymer)

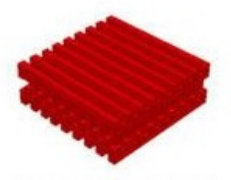

Ceramic scaffold

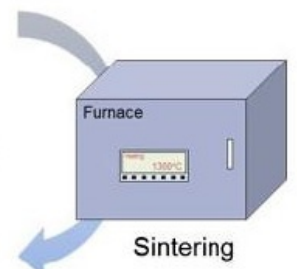

Figure 1. Ceramic frame fabrication procedure. ${ }^{17}$ 


\section{Pressure}

Monomer polymerisation leads to volume shrinkage and internal stress. ${ }^{25-27}$ Depending on the type of monomer, degree of conversion, type of initiators, and type of polymerization reaction, a volume reduction can be about $1.5-3.6 \% .{ }^{28}$ For a bulky compact, because of its 3-D capillary structure and polymerization toward the center, the volume reduction creates defects, such as interior pores. For rigid sintered network, an interfacial debonding between polymer and ceramic network could take place. Under pressure, a permanent flow of monomer to the polymerization sites makes it possible to fill pores with liquid monomer. In this case, the monomer flow is dominated by the expanding monomer, for which reason the heating rate does not have a strong influence on monomer polymerization as well as defected inside the compact. ${ }^{7}$ Under $100 \mathrm{MPa}$ pressure, a reduced defect density was observed while no defects were found inside the pressure-induced ceramic structure (Figure 3$)^{7}$ Polymerization under pressure resulted in improved mechanical properties and stiffness due to limited shrinkage and decreased amount of material flaws by reducing free volume ${ }^{29-32}$ which also limited the development of internal stress. ${ }^{25}$ The ability to reduce flaws in materials is probably related to heterogeneity of particles. ${ }^{29}$ Further, pressure on a monomer system can decrease intermolecular distances and reduce the free volume to further affect the mechanical properties of the composites. ${ }^{33}$

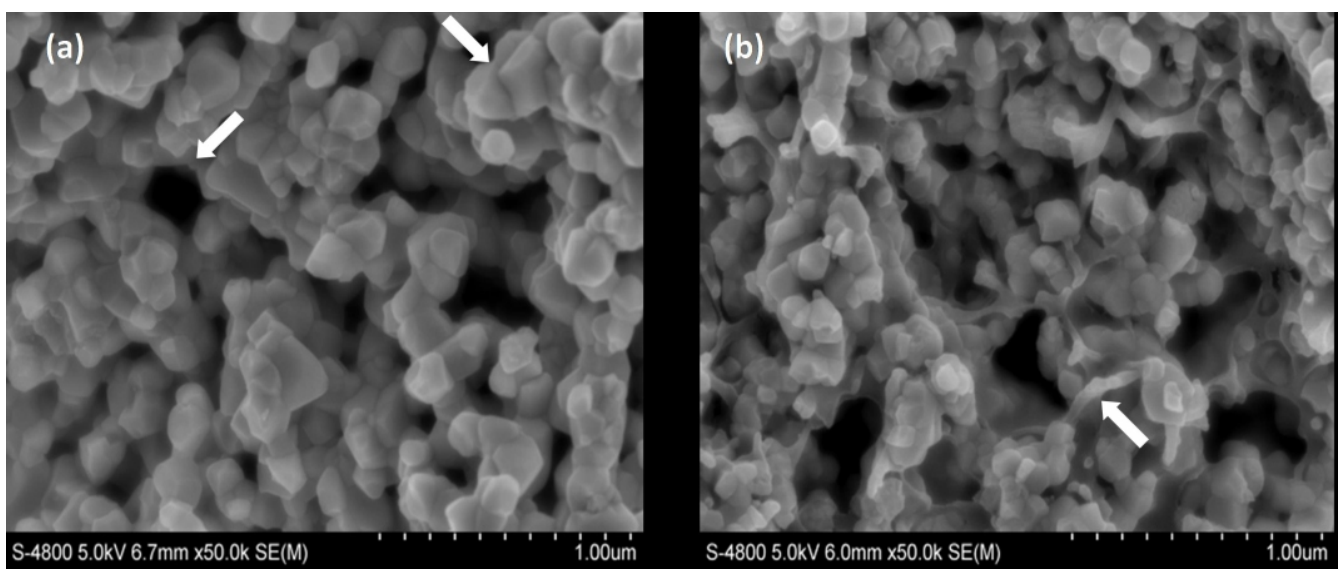

Figure 2. Microstructure of fracture surface of (a) partially sintered zirconia compact and (b)polymethyl methacrylate infiltrated zirconia hybrid composites. ${ }^{5}$

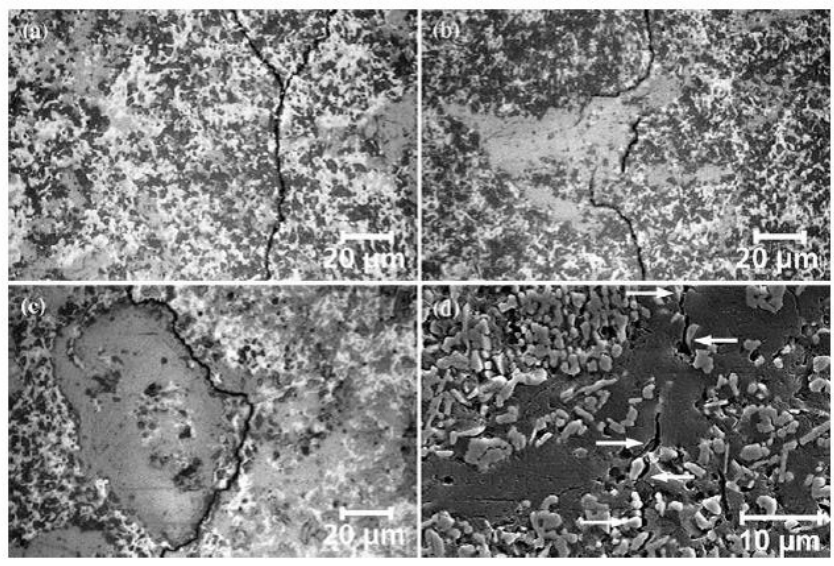

Figure 3. Cracks in pressure-induced compacts: a. crack branching; b. polymer bridging and crack deflection; c. preferred crack path along the interface; $d$. high-resolution image of a polymer bridge. The contrast and the brightness of the images $a, b$, and c in the area of the cracks were intensified. ${ }^{7}$

\section{Type of ceramic and monomer}

Material type, including both resin and filler, is the dominant factor that affects the mechanical properties of the composites. It has been well documented that ceramics have a fundamental weakness in that they are easily fractured and require high-temperature sintering. It is possible to tune the properties by changing the grain size distribution, grain density, and sintering parameters including temperature and time. For example, a more rigid and denser network with higher flexural modulus could be achieved by increasing sintering 
time and temperature. ${ }^{25}$ In addition, ceramics, such as zirconia frameworks, are less translucent than natural teeth and require veneering to achieve optimum esthetics. Porous materials, due to the light refraction at the interfaces, exhibit a mismatch of refractive index between resin and ceramic, thus results in opaque materials along interfaces between the resin and ceramic, which could refract light and increase the opacity. In resin infiltrated ceramic hybrid materials, the lower refractive index of resin (1.48-1.53 of methacrylate monomers) can reduce hybrid materials' overall refractive index compared to the ceramic composition of the materials (1.78 for alumina and 2.13 for zirconia) due to the uniform distribution of the monomer inside the compact. ${ }^{34}$

$$
n=\frac{n_{1} V_{1}+n_{2} V_{2}}{V_{1}+V_{2}}
$$

where, $n$ represents the refractive indexes and $V$ volume fraction.

The polymer infiltration technique has been adapted for improvement in fracture toughness of the porous ceramic scaffolds. A number of infiltrating polymers, including poly(glycolic acid), poly(lactic acid), poly(D,L-lactic-co-glycolic acid), and polycaprolactone (PCL) have been used in preparation composites for orthopedic applications. ${ }^{17,35-38}$ For example, PCL and polycaprolactone fumarate (PCLF) were typical procedure for infiltrating the hydroxyapatite (HA) scaffolds includes immersion of samples in $50 \mathrm{~mL}$ of infiltration solution at room temperature for $24 \mathrm{~h}$. Then, the wet blocks were transferred to a vacuum oven $(0.3 \mathrm{~atm})$ and were kept there for $20 \mathrm{~min}$ to evaporate the solvent. The samples were cured for $2 \mathrm{~h}$ at $90^{\circ} \mathrm{C}$ to induce the curing reaction and then $2 \mathrm{~h}$ at $120^{\circ} \mathrm{C}$ in a forced air convection oven to complete the crosslinking reaction. In preparation of $\mathrm{PCL}$ infiltrated ceramic scaffolds under low vacuum, the PCL solution replaces the air in the micropores and fills about $81 \%$ of the volume of the micropores. The compressive strength and toughness of the ceramic/polymer scaffolds are about twice of that of the ceramic scaffolds. The ceramic/polymer hybrid scaffold could withstand higher external stress and energy as compared to ceramic scaffolds. The infiltrating PCL filled micropores hold the ceramic particles together. When the ceramic structure breaks, the infiltrated PCL is strained, which results in the formation of PCL fibril that bridges the crack surfaces of the ceramic structure (Figure 4).
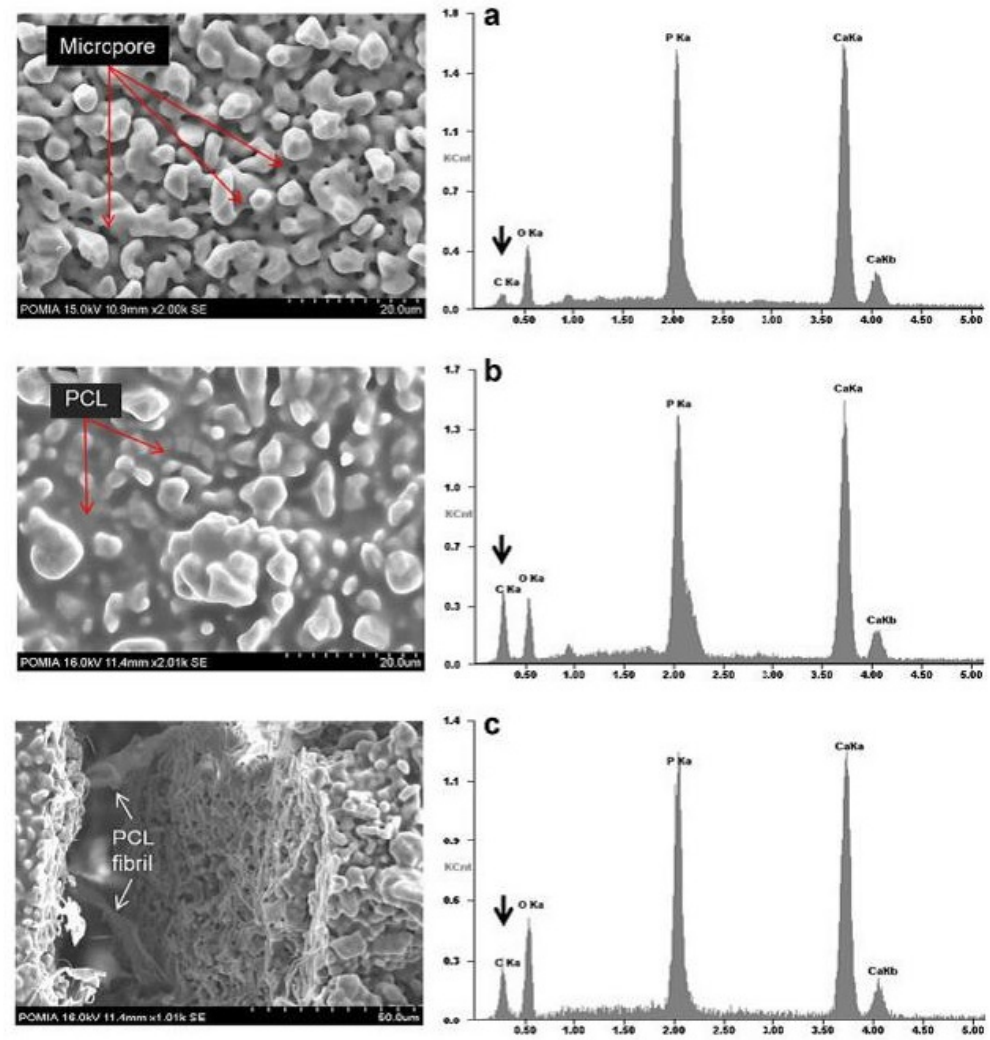

Figure 4. SEM images and EDX spectra of scaffolds showing (a) the ceramic scaffold top surface; (b) ceramic/polymer scaffold top surface; and (c) ceramic polymer scaffold fracture surface. Black arrows indicate carbon. ${ }^{17}$ 
Prepolymer of polyurethane acrylates (PUA), with low viscosity, is well infiltrated into the porous aluminium oxide $\left(\mathrm{Al}_{2} \mathrm{O}_{3}\right)$ matrix to form mechanically strong and tough polymer infiltrated ceramic composites. ${ }^{39}$ The mechanical properties are improved by the distribution of stress between heterophases in the $\mathrm{PUA}-\mathrm{Al}_{2} \mathrm{O}_{3}$ composite, thereby increasing the functionality of the polymer. Functional polymer with ionic bonds with inorganic phase of (calcium polyphosphate) creates strong polymer infiltrated ceramic composites (resulting in seven-fold improvement of bending strength). ${ }^{40}$ Epoxy infiltrates into HA obtained from bones via deorganification in hot sodium hydroxide $(\mathrm{NaOH})$ solution. The polymer content in the composite reaches to $36 \%$ by weight and $92 \%$ of the theoretical density. Interaction between resin and $\mathrm{HA}$ reduces interface segment mobility and increases the glass transition temperature of epoxy contributing to improved mechanical properties. ${ }^{41}$

\section{Sintering condition}

Sintering affects the mechanical properties of the ceramic structure. The shrinkage ratio at sintering temperature $\left(1400^{\circ} \mathrm{C}\right)$ can be a factor influencing the design and ceramic matrix or scaffolds. Gaps in ceramic particles generate micropores when ceramic particles adhere to each other. In addition, the more sintered the network is, the more sintering necks exist, which increases the strength of the network. ${ }^{25}$ Increase in heating rate results in increased shrinkage rate. The shrinkage can be analyzed by converting into relative density using the following equation:

$$
\rho=\left(\frac{1}{1-d L / L_{0}}\right)^{3} \rho_{0}
$$

where, $d L / L_{0}$ is the linear shrinkage obtained from the dilatometric experiment and is the initial relative density of the material.

\section{Mechanical properties}

Properties such as elastic modulus or stiffness enable a better understanding of a dental restorative material behavior during implementation. The flexural strength of the porous ceramic can be enhanced by polymer infiltration and porous ceramic-polymer ratio, which affects the flexural strength of the ceramic-polymer hybrid composites. In a ceramic/polymer hybrid composite, the ceramic network with the lowest density (the highest porosity) showed the highest flexural strength of $160 \pm 8.5 \mathrm{MPa} .{ }^{42}$ Compared to PSZC, the fracture toughness of PMMA infiltrated zirconia compacts improved from 1.71 to $4.60 \mathrm{MPa} \cdot \mathrm{m}^{1 / 2}$ (Table 1). After eliminating the open pores of PSZC, the crack initiating effect was reduced, which induced significant improvement of the flexural strength from 161.2 to $202.6 \mathrm{MPa}$. A commercially available resin-based composite exhibits a flexural strength of $120.7 \mathrm{MPa}$. ${ }^{5,6}$ The strength enhancement is attributed to the interactions between the polymer and the alumina at the alumina-polymer interface. ${ }^{24}$ This increase in enhancement suggests that these interactions are most pronounced when acrylate-based polymers are incorporated. These findings along others have confirmed that mechanical properties of polymer infiltrated ceramic composites were close to that of human dentin and enamel. ${ }^{1,16,43}$

Table 1. Mechanical properties of PSZC, PZC, and a resin-based composite ${ }^{5,6}$

\begin{tabular}{|l|l|l|l|l|}
\hline Materials & $\begin{array}{l}\text { Flexural } \\
\text { strength } \\
(\mathrm{MPa})\end{array}$ & $\begin{array}{l}\text { Elastic } \\
\text { modulus } \\
(\mathbf{G P a})\end{array}$ & $\begin{array}{l}\text { Vickers } \\
\text { hardness } \\
(\mathrm{GPa})\end{array}$ & $\begin{array}{l}\text { Fracture } \\
\text { toughness } \\
\left(\mathbf{M P a} \cdot \mathbf{m}^{\mathbf{1} 2}\right)\end{array}$ \\
\hline PSZC-70\% & $161.2 \pm 8.6$ & $47.6 \pm 3.4$ & & $1.71 \pm 0.11$ \\
\hline PZC-70\% & $202.6 \pm 12.1$ & $58.7 \pm 4.0$ & $3.60 \pm 0.34$ & $4.60 \pm 0.26$ \\
\hline Resin composite* & $120.7 \pm 10.8$ & $10.3 \pm 0.8$ & $0.51 \pm 0.04$ & $1.20 \pm 0.11$ \\
\hline
\end{tabular}

\footnotetext{
*Nissin Dental Product Inc., Japan.
}

\section{Machinability}

The relevance to CAD/CAM generated restorations of PICNs is its machinability. ${ }^{16}$ Machinability involves material deformation and microfracture. The brittleness index (BI), a ratio between the hardness to fracture toughness integrating the dual responses, is considered as quantification criteria of the machinability rather than a simple comparison of either the hardness or the fracture toughness. The BI varies among materials, such as 0.1 
$\mu \mathrm{m}^{-1 / 2}$ for steel and $17 \mu \mathrm{m}^{-1 / 2}$ for Si monocrystal. Typically, the BI for glasses and ceramics ranges from 3 to $9 \mu \mathrm{m}^{-1 / 2} \cdot{ }^{44,45}$ Appropriate machinability usually occurs when the material has a value of $\mathrm{BI}$ lower than $4.3 \mu \mathrm{m}^{-1 / 2} .{ }^{46}$ In as much, the PZC and the commercial resin composite has a value $\mathrm{BI}$ of $0.78 \mu \mathrm{m}^{-1 / 2}$ and $0.43 \mu \mathrm{m}^{-1 / 2}$, respectively. The results suggest that $\mathrm{PZC}$ has better machinability than glasses and ceramics, while has machinability similar to that of a resin composite. ${ }^{5}$

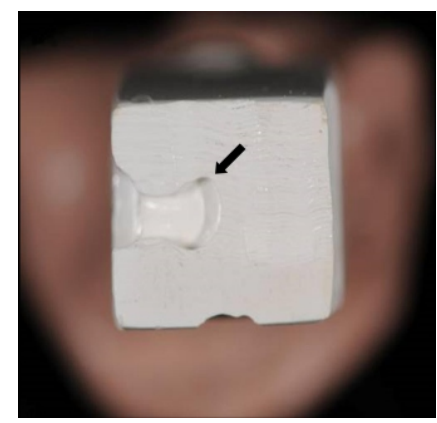

Figure 5. Class II cavities machined using a dental drill on PZC. ${ }^{5}$

Machining time on polymer infiltrated ceramic hybrid materials represents an economic consideration adapting these new materials to operative dentistry, particularly for chair-side CAD/CAM. Drilling a Class II cavity on a PZC blank requires 12.8 minutes compared to 8.5 minutes for commercial resin composites. The cutting surfaces of the Class II cavity on PZC$70 \%$ remain smooth and the dimensions remain unchanged (Figure 5). These results further demonstrate that $\mathrm{PZC}-70 \%$ has comparable machinability with that of commercial resin composite. $^{5}$

These findings suggest that polymer infiltrated ceramic composites exhibit improved flexibility, fracture toughness, better machinability, reduced brittleness, rigidity, and hardness as compared to ceramics. ${ }^{16}$

\section{Other structures}

\section{Brick-motor structure}

In natural hard tissues, such as enamel, and brittle mineral particles, such as $\mathrm{HA}$, are interconnected by a small amount of soft and compliant protein such as tyrosine-rich amelogenin generating excellent strength, modulus, and toughness. ${ }^{47}$ It is believed that the internal arrangement of minerals in anisotropic and hierarchical structure contributes to the properties of these materials. The brick-motor structure obtained through the schematically presented process suggests that it is possible to synthesize multi-level hierarchical composite materials with arbitrarily chosen ceramic and polymer at tunable volume ratios. This technique potentially can be adapted to fabricate multi-level hierarchical polymer infiltrated ceramic composites as dental restoration materials.

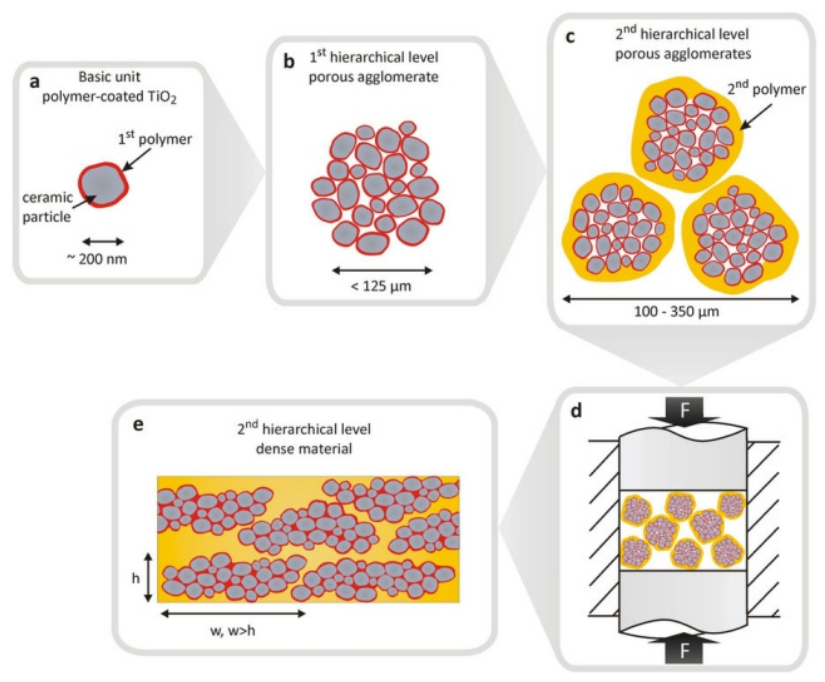

Figure 6. Synthesis of a hierarchical material. (a) The basic building units are primary ceramic particles encapsulated with PMMAin radical emulsion polymerization. (b). Porous agglomerates of several coated particles build the first level of hierarchy. (c). First level of hierarchy agglomerates is coated on a second polymer in a spouted bed process in order to create agglomerates of the second level of hierarchy. 
(d). Second level of hierarchy agglomerates are unidirectional hot-pressed, yielding; (d). Dense materials with anisotropic microstructures. ${ }^{47}$

\section{Biomimetic indirect dental composites}

Biomimetic composites having multi-level hierarchical structure by infiltrating organic resin into their inorganic components are used for indirect dental restorations (Figure 7). The advantages of biomimetic composites are similar to those of resin composites, i.e., a less invasive tooth preparation, without high level of abrasion on antagonizing teeth, possibility to repair alteration with the same resin from which it is made, and the chemical compatibility with adhesive resin cements. ${ }^{48}$

A

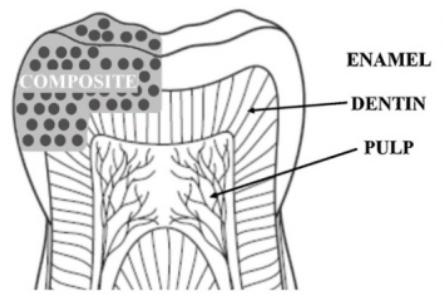

B

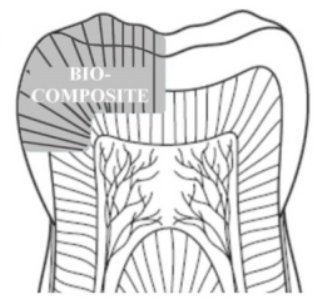

D
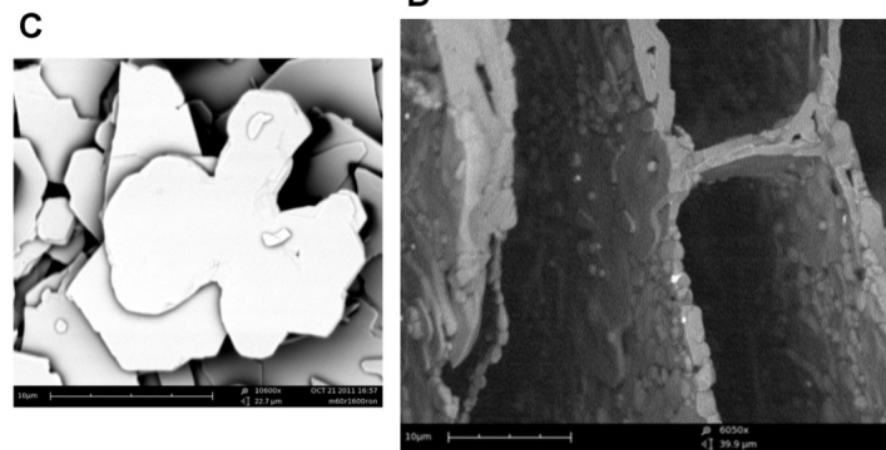

Figure 7. Schematic structure of an indirect restoration with conventional composite; (A) and with the biomimetic ceramic composite produced using freeze casting and polymer infiltration techniques (B). The anisotropic feature of the biomimetic ceramic composite makes it more similar to natural dentin than the random arrangement of the conventional composites. (C) SEM image of RonaFlair ${ }^{\circ}$ white sapphire powder; and (D) cross-section of a freeze-cast ceramic after sintering. It can be seen that freeze casting, starting from particles with a plate-like morphology with size of $<16 \mu \mathrm{m}$, is able to control crystal growth by aligning plate-like particles and create uniform lamellae morphology. ${ }^{48}$

Biomimetic approach to restorative dentistry is desirable through the structural design of "tooth-like" restorative materials to mimic enamel and dentin. The ceramic/polymer hybrid composites fabricated by the infiltration of a polymer resin with a hierarchically structured ceramic perform offers an opportunity for possible indirect restorations mimicking the aligned structure of dentinal tubules and reproduce the feature of anisotropy. The freeze casting method produced an aligned and graded structure in the ceramic phase with lamellae-like morphology. These ceramic/resin hybrid materials also exhibit anisotropy characteristics. ${ }^{48}$

\section{Replamine form process}

Porous replamine form ceramic, metal, and polymer provide an opportunity for rapid stabilization of the prosthetic materials by ingrowth of tissue into the porous network. ${ }^{49,50}$ This process can also lead to a ceramic/polymer anastomosing composite with interpenetrating structure. Materials, such as $\mathrm{HA}_{2} \mathrm{Al}_{2} \mathrm{O}_{3}, \mathrm{TiO}_{2}$, silver, Co-Cr-Mo alloys, and polymers, have been successfully prepared by the replamine form process. ${ }^{51}$ The interconnected pores enable a ceramic/polymer anastomosing composite with interpenetrating structure.

\section{Perspective}

Infiltrating monomers into porous ceramic or glass-ceramic network allowed us to overcome the limitation of incorporating high amount of ceramic fillers into polymer matrix by conventional mixing. The microstructure geometry and mechanical properties of polymer infiltrated ceramic hybrid composites can be further enhanced by appropriate material design and processing technique, which is of significant importance for academic research as well as for practical application, particularly in CAD/CAM technology. Further improvements in properties would be to impart comparable wear resistance toward opposing tooth and to 
match the mechanical behaviors with natural tooth.

\section{Acknowledgement}

The authors appreciate financial support from the Shaanxi Province Social Development Research Project (2014SF2-07) and Military Health Research Program (13QNP137). 


\section{References}

1. He LH, Swain M. Anovel polymer infiltrated ceramic dental material. Dent Mater. 2011; 27: 527-534.

2. Karapetian VE, Sorg T, Jockel M, Baumann MA. Comparison of different polishing systems for inlay ceramics. In: Morrmann WH, edit. CAD/CAM in aesthetic dentistry. Chicago: Quintessence Publishing Co., Inc.; 1996.

3. Donovan TE. Factors essential for successful all-ceramic restorations. J Am Dent Assoc. 2008; 139:14S-18S.

4. Heintze SD, Cavalleri A, Forjanic M, Zellweger G, Rousson V. Wear of ceramic and antagonist-a systematic evaluation of influencing factors in vitro. Dent Mater. 2008; 24: 433-449.

5. Li S, Zhao Y, Zhang JF, Xie C, Zhao X. Machinability of poly(methyle methacrylate) infiltrated zirconia hybrid composites. Mater Lett. 2014; 131:347-349.

6. Li S, Zhao Y, Zhang JF, et al. Mechanical properties and microstructure of $\mathrm{PMMA} \mathrm{ZrO} \mathrm{O}_{2}$ nano composites for dental CAD/CAM. Adv MaterRes. 2013; 785-786: 533-536.

7. Steier VF, Koplin C, Kailer A. Influence of pressure-assisted polymerization on the microstructure and strength of polymer-infiltrated ceramics. J Mater Sci. 2013; 48: 3239-3247.

8. Braem M, Finger W, Van Doren VE, Lambrechts P, Vanherle G. Mechanical properties and filler fraction of dental composites. Dent Mater. 1989; 5: 346-349.

9. Urabe H, Nomura Y, Shirai K, Yoshioka M, Shintani H. Effect of filler content and size to properties of composite resins on microwave curing. J Mater Sci Mater Med. 1999; 10: 375-378.

10. Mendes SF, Costa CM, Caparros C, Sencadas V, Lanceros-Mendez S. Effect of filler size and concentration on the structure and properties of poly(vinylidene fluoride)/BaTiO ${ }_{3}$ nanocomposites. $J$ Mater Sci. 2012; 47: 1378-1388.

11. Halvorson R, Erickson R, Davidson C. The effect of filler and silane content on conversion of resinbased composite. Dent Mater. 2003; 19: 327-333.

12. Ferracane JL. Resin composite—State of the art. Dent Mater. 2011;27:29-38.

13. Cramer NB, Stansbury JW, Bowman CN. Recent advances and developments in composite dental restorative materials. J Dent Res. 2011; 90: 402-416.

14. Ferracane JL. Resin-based composite performance: Are there some things we can't predict? Dent Mater. 2013; 29: 51-58.

15. Drumond JL. Degradation, fatigue, and failure of resin dental composite materials. J Dent Res. 2008; 87: 710-719.

16. Coldea A, Swain MV, Thiel N. Mechanical properties of polymer-infiltrated-ceramic-network materials. Dent Mater. 2013; 29: 419-426.

17. Seol YJ, Park DY, Kim SW, Park SJ, Cho DW. A new method of fabricating robust freeform 3D ceramic scaffolds for bone tissue regeneration. Biotechnol Bioeng. 2013; 110: 1444-1455.

18. Boczkowska A, Konopka K, Kurzydlowski KJ. Effect of elastomer structure on ceramic-elastomer composite properties. J Mater Process Technol. 2006; 175: 40-44.

19. Gomez de Salaza JM, Barrena MI, Morales G, Matesanz L, Merino N. Compression strength and wear resistance of ceramic foams-polymer composites. Mater Lett. 2006; 60: 1687-1692.

20. Prehn R, Haupert F, Friedrich K. Sliding wear performance of polymer composites under abrasive and water lubricated conditions for pump applications. Wear. 2005; 259: 693-696.

21. Mohamad YD, Bretcanu O, Boccaccini A. Polymer-bioceramic composites for tissue engineering scaffolds. J Mater Sci. 2008; 43: 4433-4442.

22. Nakahira A, Tamai M, Miki S, Pezzotti G. Fracture behavior and biocompatibility evaluation of nyloninfiltrated porous hydroxyapatite. J Mater Sci. 2002; 37: 4425-4430.

23. Matinlinna JP, Lassila LV, Ozcan M, Yli-Urpo A, Vallittu PK. An introduction to silanes and their clinical applications in dentistry. Int J Prosthodont. 2004; 17: 155-164.

24. Abdala AA, Milius DL, Adamson DH, Aksay IA, Prud'homme RK. Inspired by abalone shell: Strengthening of porous ceramics with polymers. Polym Mater Sci Eng. 2004; 90: 385-386. 
25. Nguyen JF, Ruse D, Phan AC, Sadoun MJ. High-temperature-pressure polymerized resin-infiltrated ceramic networks. J Dent Res. 2014; 93: 62-67.

26. Ferracane JL. Developing a more complete understanding of stresses produced in dental composites during polymerization. Dent Mater. 2005; 21: 36-42.

27. Park JW, Ferracane JL. Residual stress in composites with the thin-ring-slitting approach. J Dent Res. 2006; 85: 945-949.

28. Bandyopadhyay S. A study of the volumetric setting shrinkage of some dental materials. $J$ Biomed MaterRes A. 1982; 16: 135-144.

29. Brosh T, Ferstand N, Cardash H, Baharav H. Effect of polymerization under pressure on indirect tensile mechanical properties of light-polymerized composites. J Prosthet Dent. 2002; 88: 381-387.

30. Kwiatkowski P, Jurczak J, Pietrasik J, et al. High molecular weight polymethacrylates by AGET ATRP under high pressure. Macromolecules. 2008; 41:1067-1069.

31. Kaminski K, Wrzalik R, Paluch M, Zoilio J, Roland CM. Pressure-induced polymerization of phenoxyethyl acrylate. J Physics: Condensed Matter. 2008; 20: 244121.

32. Schettino V, Bini R, Ceppatelli M, Citroni M. Activation and control of chemical reactions at very high pressure. Phys Scripta. 2008; 78: 058104.

33. Nguyen JF, Migonney V, Ruse ND, Sadoun M. Resin composite blocks via high-pressure hightemperature polymerization. Dent Mater. 2012; 28: 529-534.

34. Wiederseiner S, Andreini N, Epely-Chauvin G, Ancey C. Refactive-index and density matching in concentrated particle suspensions: a review. Exp Fuids. 2011; 50: 1183-1206.

35. Pezzotti G, Asmus SMF, Ferroni LP, Miki S. In situ polymerization into porous ceramics: A novel route to tough biomimetic materials. J Mater Sci Mater Med. 2002; 13:783-787.

36. Miao X, Lim WK, Huang X, Chen Y. Preparation and characterization of interpenetrating phased TCP/HA/PLGA composites. Mater Lett. 2005; 59: 4000-4005.

37. Shor L, Guceri S, Wen XJ, Gandhi M, Sun W. Fabrication of three-dimensional polycaprolactone/hydroxyapatite tissue scaffolds and osteoblast-scaffold interactions in vitro. Biomaterials. 2007; 28: 5291-5297.

38. Wong SC, Baji A, Gent AN. Effect of specimen thickness on fracture toughness and adhesive properties of hydroxyapatite-filled polycaprolactone. Compos A. 2008; 39: 579-587.

39. Kim EH, Jung YG, Jo CY. Microstructure and mechanical properties of heterogeneous ceramicpolymer composite using interpenetrating network. J Nanomater. 2012; 932059.

40. Yang L, Wang J, Hong J, Santerre JP, Pilliar RM. Synthesis and characterization of a novel polymer-ceramic system for biodegradable composite applications. J Biomed Mater Res. 2003; 66A: 622-632.

41. Roese PB, Amico SC, Junior WK. Thermal and microstructural characterization of epoxy-infiltrated hydroxyapatite composite. Mater Res. 2009; 12: 107-111.

42. Coldea, M.V. Swain, B.A. Just, J. Fischer, E. Bojemuller, N. Thiel. Flexural strength of hybrid ceramic depending on polymer content. IADR General Session, Seattle, WA, March 20-23, 2013.

43. He LH, Purton D, Swain MV. A novel polymer infiltrated ceramic for dental simulation. J Mater Sci Mater Medicine. 2011; 22: 1639-1643.

44. Lawn BR, Marshall DB. Hardness, toughness and brittleness: An indentation analysis. J Am Ceram Soc. 1979; 62: 347-350.

45. Sehgal J, Nakao Y, Takahashi H, Ito S. Brittleness of glasses by indentation. J Mater Sci Lett. 1995; 14: 167-169.

46. Boccaccini AR. Machinability and brittleness of glass-ceramics. J Mater Proc Tech. 1997; 65: 302-304.

47. Brandt K, Wolff MFH, Salikov V, Heinrich S, Schneider GA. A novel method for a multi-level hierarachical composite with brick and mortar structure. Sci Rep. 2013; 3: 2322.

48. Petrini M, Ferrante M, Su B. Fabrication and characterization of biomimetic ceramic/polymer composite materials for dental restoration. Dent Mater. 2013; 29: 375-381. 
49. White RA, Weber JN, White EW. Replamine form: A new process for preparing porous ceramic, metal, and polymer prosthetic materials. Science. 1972; 176: 922-924.

50. Piecuch JF. Augmentation of the atrophic edentulous ridge with porous replamine form hydroxyapatite (Interpore-200). Dent Clin North Am. 1986; 30: 291-305.

51. White EW, Weber JN, Roy DM, et al. Replamine form porous biomaterials for hard tissue implant applications. J Biomed Mater Res. 1975; 9: 23-27. 